\title{
NETNOGRAFIA: SOBRE A PESQUISA EM AMBIENTES VIRTUAIS
}

Vítor de Morais Alves Evangelista, Rita Melissa Lepre, Aline Kadooka

Universidade Estadual Paulista - UNESP, Programa de Pós-Graduação em Psicologia, Câmpus de Assis, SP. E_mail:

vitordemorais@hotmail.com

FAPESP - Fundação de Amparo à Pesquisa do Estado de São Paulo

\section{RESUMO}

Com as novas formas de organização social e da virtualidade insurgente, frutos da pósmodernidade, os pesquisadores devem adaptar seus métodos a fim de capturar as melhores evidências, e a etnografia, enquanto descrição do comportamento humano e da cultura organizacional baseada na observação, vem sofrendo essa adaptação. O presente artigo tem o objetivo de fazer uma breve discussão sobre a etnografia quando empregada como metodologia de pesquisa direcionada ao estudo sobre as relações virtuais ou aquelas pertencentes à cibercultura. Devemos entender que as técnicas etnográficas podem e devem se tornar um importante instrumento de intervenção cujo potencial está em produzir a reflexão sobre a própria prática. Dessa forma torna-se essencial prolongar as discussões em torno dos aspectos epistemológicos e ontológicos seja da etnografia virtual ou da própria etnografia.

Palavras-chave: etnografia, netnografia, virtual, metodologia, pós-modernidade.

\section{NETNOGRAPHY : ON RESEARCH IN VIRTUAL ENVIRONMENTS}

\begin{abstract}
With new forms of social organization and insurgent virtuality, fruits of postmodernity, the researchers must adapt their methods in order to capture the best evidences, and ethnography, as a description of human behavior and organizational culture based on observation, came suffering this adaptation. This article aims to make a brief discussion of ethnography when employed as a research methodology aimed at the study of virtual relationships or those belonging to cyberculture. We must understand that the ethnographic techniques can and should become an important intervention instrument whose potential is to produce a reflection on the own practice. Thus it becomes essential to prolong the discussions around the epistemological and ontological aspects in the virtual ethnography or the ethnography itself.
\end{abstract}

Keywords: ethnography, nethnography, virtual, methodology, postmodernity 


\section{INTRODUÇÃO}

Podemos caracterizar a atual sociedade, a era do software e individualidade, como imersa em uma modernidade líquida, usando a ideia de liquidez em oposição à solidez, que seria a metáfora apropriada da primeira modernidade, na qual os indivíduos constantemente buscam suas identidades frente à instantaneidade do tempo e das relações. Tal liquidez estaria invadindo todos os setores da modernidade que antes eram tidos como sólidos. O indivíduo torna-se cada vez mais apto a escolher, dentre as opções dispostas pelo mercado ao consumo. Embora as possibilidades de escolha sejam infindas, isso não faz dos indivíduos pessoas mais felizes, pois, as consequências de uma má escolha tendem a recair sobre o indivíduo de forma fulminante, visto a não existência de bases sólidas nas quais se pode apoiar. Giddens (1991) caracteriza a sociedade moderna direcionada ao contexto do virtual. Com os avanços no plano técnico e teórico, a humanidade passou a acreditar que percorria uma linha contínua em direção ao desenvolvimento e a certeza divina foi substituída pela certeza na razão científica ou o desencantamento do mundo.

O presente trabalho tem o objetivo de fazer uma breve discussão sobre a etnografia quando empregada como metodologia de pesquisa direcionada ao estudo sobre as relações virtuais ou pertencentes à cibercultura. Para tanto, apontaremos de forma sucinta algumas definições de Pierre Lévy, Marc Augé e Jean Baudrillard sobre virtualização e os não-lugares e posteriormente ressaltaremos alguns pontos tanto da etnografia virtual quanto da netnografia analisando suas semelhanças e principais direcionamentos.

\section{O VIRTUAL E A CIBERCULTURA}

A superação das barreiras geográficas e temporais propiciou o virtual como nova forma de socialização e parte integrante da atual constituição de uma sociedade individualista. $O$ virtual é criado em um espaço peculiar, onde se cria uma dimensão na qual o indivíduo imerge em um mundo com diferentes possibilidades, personalidades e poderes, um "oásis em meio às regras e convenções" da realidade. (MELLO E CASTRO, 2012, p.2). Turkle (1995), ainda na década de 1990, argumentava que as fronteiras entre o real e o virtual, entre o animado e o inanimado e entre $o$ self unitário e o múltiplo estariam se desfazendo apresentando mudanças fundamentais no modo como criamos e experienciamos a identidade humana. $\mathrm{O}$ termo cibercultura nos remete a ideia de que existem algumas culturas singulares nas quais as novas tecnologias se baseiam e que tendem a contribuir inversamente.

Pierre Lévy (2011) relata que o movimento de virtualização afeta hoje não apenas a informação e a comunicação, mas também os corpos. A virtualização atinge as modalidades do estar junto e a própria constituição de nós. Diferente da visão apocalíptica da virtualização de Baudrillard sobre o desaparecimento do universo, Lévy considera a virtualização como a essência da mutação das técnicas, da economia e dos costumes. A virtualização, portanto, possui um caráter não negativo nem tampouco positivo, ela é neutra e apresenta-se como a heterogênese do humano, ou o movimento mesmo do "devir outro". Para o autor torna-se imprescindível aprender, pensar e compreender o processo de virtualização. Contudo, Lévy, ressalta uma concepção falsa sobre o real e o virtual. Relata que no uso corrente a palavra virtual é empregada com frequência como significado da ausência de existência, de realidade. Dessa forma errônea o real seria da ordem do tenho e o virtual da ordem do terás, ou da ilusão. Em termos filosóficos, o virtual não se deve opor ao real, mas ao atual: "virtualidade e atualidade são apenas duas maneiras de ser diferentes".

Lévy é categórico ao definir ciberespaço e cibercultura:

O ciberespaço (que também chamarei de rede) é o novo meio de comunicação que surge da interconexão mundial dos computadores. 0 termo especifica não apenas a infraestrutura material da comunicação digital, mas também o universo oceânico de informações que ela abriga, 
assim como os seres humanos que navegam e alimentam desse universo. Quanto ao neologismo cibercultura, especifica aqui o conjunto de técnicas (materiais e intelectuais), de práticas, de atitudes, de modos de pensamento e de valores que se desenvolvem juntamente com crescimento do ciberespaço. (LÉVY, 2011, p.17)

A questão acerca da cibercultura com a interface da comunicação estrutura se em torno da inserção das tecnologias de informação e comunicação no mundo contemporâneo. "É aí, portanto, nesse lugar sem distâncias físicas, que terá lugar a competição entre as empresas planetárias e, cada vez mais, entre as empresas locais. O nervo do comércio se torna o tráfego da atenção no ciberespaço" (LÉVY, 2011, p.177).

Para Augé (1994) a supermodernidade é produtora de não-lugares, ou seja, espaços que não são em si lugares antropológicos e que contrariamente à modernidade de Baudelaire, não integram os lugares antigos, classificados e promovidos à lugares de memória. O conceito augeriano de não lugar, fornece, segundo Rocha e Montardo (2005), uma conexão da antropologia e da cibercultura: "O não-lugar pode existir como lugar, destacando ainda que lugar e não-lugar são polaridades fugidias: o primeiro nunca é completamente acabado e o segundo nunca se realiza completamente" (p.7). Augé nos fornece discussões sobre ambientes criados pela supermodernidade, que se multiplicam na forma de não-lugares, o que para ele trata-se de um fenômeno modificador de nossa percepção espaço temporal. O não-lugar é o oposto do lugar; não é relacional ou histórico.

Com uma visão diferente, Baudrillard classifica o virtual como uma criação de uma realidade imaginada, e que devido ao avanço tecnológico parece real, mais real que a própria realidade. O virtual é, portanto, um simulacro, onde somente se apresenta com real. Tal capacidade da comunicação virtual em simular o real acaba por gerir o esvaziamento do processo comunicacional.

não podemos nem imaginar o quanto o virtual já transformou, como que por antecipação, todas as representações que temos do mundo. Não podemos imaginá-lo, pois o virtual caracteriza-se por não somente eliminar a realidade, mas também a imaginação do real, do político, do social - não somente a realidade do tempo, mas a imaginação do passado e do futuro (BAUDRILLARD, 1999, pp. 71-72).

Em Simulacros e Simulação (1991) Baudrillard aponta que a realidade deixou de existir, e estamos a viver em uma representação da realidade, difundida, na sociedade pós-moderna, pela mídia. Baudrillard exalta o fato de que vivemos em uma época onde os símbolos têm mais força do que a própria realidade. Deste fenômeno derivam-se os "simulacros", simulações do real que, parecem ser mais atraentes ao indivíduo do que o verdadeiro objeto.

\section{ETNOGRAFIA VIRTUAL E NETNOGRAFIA}

Diante das novas formas de organização social e da emergência das comunidades virtuais, frutos da pós-modernidade ou supermodernidade, os pesquisadores devem adaptar seus métodos a fim de capturar as melhores evidências e a etnografia, enquanto descrição do comportamento humano e da cultura organizacional baseada na observação vem sofrendo essa adaptação. A visão mais estabelecida sobre a etnografia está intrínseca à antropologia como um método singular de observação. Sobre o uso do termo etnografia no contexto de pesquisa online, Mitsuichi (2007) aponta que tal uso é determinado pela ideia ou construção do ciberespaço. Mais especificamente pelo fato de que toda cultura está inserida em um espaço e a etnografia está apta a investigar 
outras formas de cultura. A noção de comunidade, um importante fator para o entendimento antropológico, muitas vezes é considerada ilusória no contexto online.

A etnografia é um termo complexo que adquire diferentes concepções dependendo de como é apropriada por determinada área de estudo. Torna-se importante ressaltar que a etnografia pode ser considerada tanto como método como produto da pesquisa. Geertz (1978) considerava a etnografia tanto quanto um processo e método da pesquisa qualitativa quanto um produto cujo objetivo estaria na interpretação cultural. Dessa forma a etnografia seria mais uma descrição densa de determinada cultura do que um conjunto de técnicas e procedimentos.

Praticar a etnografia é estabelecer relações, selecionar informantes, transcrever textos, levantar genealogias, mapear campos, manter um diário, e assim por diante. Mas não são essas coisas, as técnicas e os processos determinados, que definem o empreendimento. $O$ que o define é o tipo de esforço intelectual que ele representa: um risco elaborado para uma "descrição densa", tomando emprestada uma noção de Gilbert Ryle. (GEERTZ, 1978, p. 15)

Polivanov (2013) aponta que a função do etnógrafo vai além de simplesmente reportar os eventos e experiências observados, cabendo ao etnógrafo explicar como tais experiências e dinâmicas sociais formam as teias de significado, que segundo Max Weber, o homem seria um ser atrelado às teias de significados tecidas por ele próprio. Para Hine (1998) a etnografia virtual é uma forma de trazer ao foco tanto os pressupostos da base etnográfica quanto as características especiais referentes as novas tecnologias envolvidas.

Kozinets (2007) relata sobre a transformação dos mundos sociais em mudo digitais e sobre a necessidade, caso queira compreender a sociedade, de seguir as atividades sociais e interações das pessoas nos mais variados meios de comunicação mediados pela tecnologia, em especial a internet. Para Kozinets (1997), a netnografia exige combinação imersiva entre participação e observação cultural com relação às comunidades pesquisadas, sendo que o pesquisador deve ser reconhecido como um membro da cultura, um elemento importante do trabalho de campo. 0 autor ainda destaca que é possível combinar dados netnográficos com outros métodos, como entrevistas, grupos focais, etc., com o intuito de se obter uma compreensão mais ampla sobre a população estudada.

A netnografia surge direcionada à pesquisa de consumidores, e se propõe a analisar fenômenos online, como comunidades, newgroups, salas de bate-papo, lista de e-mails, grupos de discussões e homepages. Portanto, as relações e interações desenvolvidas em uma dimensão virtual afetavam os comportamentos fora dessa virtualidade. Netnografia, em princípio, referia-se a uma descrição de uma cultura online por intermédio da antropologia cultural. Com o passar o tempo o recorte se tornou mais específico portando características mais detalhadas de cunho qualitativo visando a investigação de culturas e comunidades presentes na internet. (KOZINETS, 1997). A netnografia surge como uma forma especializada da etnografia adaptada às contingências específicas dos mundos sociais atuais se tornando uma ferramenta essencial para pesquisas relacionadas ao marketing e ao consumo. Para Kozinets (2007) tal pesquisa incorpora visões de diversos campos, tais como antropologia, sociologia e estudos culturais.

Noveli (2010) aponta que a netnografia mantém a orientação etnográfica por estudar culturas e grupos. A principal diferença com a etnografia tradicional estaria na primeira parte da investigação destinada ao discurso no contexto. Enquanto a etnografia possui o contato frente a frente com o indivíduo, face a face, a netnografia não possui essa certeza com relação ao indivíduo estudado. Hine (2000) ressalta que o etnógrafo habita em um mundo intermediário, sendo um estranho e ao mesmo tempo um nativo, tendo que cercar-se tanto da cultura como tentar manter a distância necessária. Para a autora é necessário escolher o grau de inserção em certa 
comunidade, especificamente o tipo de observação ao relatar as considerações ao seu objeto. Afirma que a etnografia, em sua forma básica, consiste em proporcionar que o pesquisador adentre ao universo que estuda por um determinado tempo, levando em consideração as relações que se formam entre aqueles que participam dos processos sociais, o pesquisador, e os sujeitos do grupo social estudado.

O etnógrafo não é um simples voyeur ou um observador desengajado, mas é, em certo sentido, um participante compartilhando algumas das preocupações, emoções e compromissos dos sujeitos pesquisados. Essa forma estendida depende também da interação, em um constante questionamento do que é possuir uma compreensão etnográfica do fenômeno (HINE, 1998, p.47).

A autora defende a utilização da etnografia virtual como metodologia para suprir o espaço de estudo das práticas cotidianas em torno da internet. Hine (2000) foi uma das pioneiras na utilização do método etnográfico em ambientes virtuais procurando problematizar sua utilização ao analisar as interações sociais em comunidades virtuais. Utilizando o termo etnografia virtual, a autora propõe o entendimento da internet em duas perspectivas: enquanto cultura e enquanto artefato cultural. A primeira perspectiva propõe que a internet seja um espaço, represente um lugar onde a cultura é constituída e reconstituída enfocando o contexto cultural dos fenômenos ocorrentes no mundo virtual (POLIVANOV, 2013). Como artefato cultural a internet passa a ser um produto da cultura, um artefato com valores e significados culturais diversos, uma tecnologia das pessoas envolvidas, dando ênfase aos atores sociais e seus respectivos usos e apropriações.

Fragoso, Recuero e Amaral (2011) ressaltam uma nova perspectiva sobre a importância da internet como artefato cultural: a internet como tecnologia midiática geradora de práticas sociais. Tal perspectiva, pontuada pela convergência das mídias permite o acompanhamento das práticas e dos atores sociais em suas performances levando em conta a dimensão material onde o campo é definido durante a pesquisa e não somente a dimensão simbólica.

\section{CONSIDERAÇÕES}

Pretendemos nesse breve trabalho esboçar a discussão metodológica referente à abordagem etnográfica ao ambiente virtual, ou ciberespaço. Embora seja crucial para os estudos sobre novas formas de comunicação e tecnologias da informação, essa metodologia ainda apresenta desvantagens dentre as quais, podemos apontar os aspectos éticos no que se refere ao anonimato dos pesquisados, a impossibilidade de observar a linguagem corporal, o excesso de informação e principalmente a falsa noção de neutralidade.

Rene Lourau, eminente analista institucional, em um artigo sobre a etnografia de Malinowski, afirmava que não há um dentro e um fora do relato etnográfico. Não existe um dentro e um fora da ciência, salvo em função de uma "linha de demarcação imaginária, que jamais é dada, mas pode ser eventualmente construída pelo autor, pelo leitor ou pelo grupo-editor implicado na instituição científica" (ALTOÉ, 2004, p.273).

Embora não exista um consenso sobre a terminologia a ser usada quando empregado o método etnográfico às pesquisas envolvendo a internet, os autores que se relacionam com esse tipo de pesquisa parecem possuir a mesma opinião no que se refere à necessidade de novas propostas e estudos relacionados às pesquisas no âmbito virtual. Todo o enorme fluxo de informações, a ruptura de paradigmas modernos e a dificuldade em se definir questões referentes ao tempo e espaço na virtualidade interferem de forma incisiva no critério metodológico a ser desenvolvido em pesquisas etnográficas. Acima de tudo, devemos entender que as técnicas etnográficas podem e devem se tornar um importante instrumento de intervenção cujo potencial está em produzir a reflexão sobre a própria prática. Dessa forma torna-se essencial prolongar as 
discussões em torno dos aspectos epistemológicos e ontológicos seja da etnografia virtual ou da própria etnografia.

\section{REFERÊNCIAS}

ALTOÉ, S. (Org.). René Lourau: analista institucional em tempo integral. São Paulo: Hucitec, 2004.

AUGÉ, M. Não lugares. Introdução a uma antropologia da supermodernidade. Campinas, SP: Papirus, 1994.

BAUDRILLARD, J. Simulacros e simulação. Lisboa: Relógio d’ Água, 1991.

.Tela total: mito-ironias da era do virtual e da imagem. Porto Alegre: Sulina, 1999.

FRAGOSO, S.; RECUERO, R.; AMARAL, A. Métodos de pesquisa para internet. Porto Alegre: Sulina, 2011.

GEERTZ, C. Ethos, Visão de mundo, e a análise de símbolos sagrados: In, A interpretação das culturas. Rio de Janeiro, Zahar Editores, 1978.

GIDDENS, A. As Consequências da Modernidade. São Paulo: Ed UNESP, 1991.

HINE, C. Virtual ethnography. London: SAGE Publications, 1998.

. Virtual methods: issues in social research on the internet. New York: Berg Publishers,

2000.

KOZINETS, R. V. On netnography: Initial Reflections on Consumer Research Investigations of Cyberculture. Evanston, Illinois, 1997

. Netnography 2.0. In: R. W. BELK, Handbook of Qualitative Research Methods in

Marketing. Edward Elgar Publishing, 2007.

LÉVY, P. Cibercultura. São Paulo: Editora 34, 2011.

O que é virtual? São Paulo: Editora 34, 2011.

MELLO, H; CASTRO, C. Ludosfera: o espaço lúdico virtual. Intercom - Sociedade Brasileira de Estudos Interdisciplinares da Comunicação. Fortaleza, 2012.

MITSUICHI, Y. Entre grafos e ethos: uma abordagem crítica a etnografia virtual. Lisboa: Edições afrontamento, 2007.

NOVELI, M. Do off-line para o Online: a netnografia como um método de pesquisa ou o que pode acontecer quando tentamos levar a etnografia para a internet. São Paulo: Organizações em contexto, 2010.

POLIVANOV, B. Etnografia virtual, netnografia ou apenas etnografia? Implicações e conceitos. Esferas, 2013 
ROCHA, P. J; MONTARDO, P. S. Netnografia: incursões metodológicas na cibercultura. Revista da Associação Nacional dos Programas de Pós-graduação em Comunicação. 2005.

TURKLE, S. La vida en pantalla: la identidad en la era de internet. Barcelona: Paidós, 1995. 